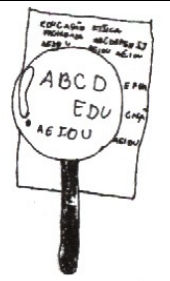

\title{
REFORMA DO ENSINO SUPERIOR: DIRETRIZES CURRICULARES EM EDUCAÇÃO FÍSICA
}

Comissão de Estudos Curriculares da FEF/UFG*

\section{RESUMO}

Neste texto tecemos algumas considerações sobre o contexto em que ocorrem os debates acerca das Diretrizes Curriculares para o ensino superior brasileiro, especialmente aquelas referentes à área de Educação Física. Sugerimos que as Diretrizes Curriculares de Educação Física, formuladas pela comissão de especialistas, designada pelo MEC, têm sido referenciadas em confronto com as perspectivas apontada para a universidade brasileira atualmente, em particular para a formação de professores. Relatamos as contribuições da FEF/UFG para este debate, bem como justificamos os pontos essenciais de um documento anterior, não publicado, em que se apresentam posições sobre currículo e formação de professores de Educação Física na atualidade. Basicamente nos opomos aos projetos do Banco Mundial, FMI e MEC/FHC e seus interesses mercadológicos e de preparação restrita para ao mercado de trabalho, por entendermos que a formação de

* Esta comissão é formada pelos professores Nivaldo A. David, Fernando Mascarenhas, Francisco de M. Netto, Anegleyce Teodoro, Marcelo Guina e pelos acadêmicos Márcio Vinícius, Orozimbo Cordeiro, Renato Mendes e Lourdecélia de Paula. 
professores deve ocorrer no âmbito da universidade pública, gratuita e de qualidade social, e onde demandas sociais relevantes se constituam no maior foco de interesse. PALAVRAS-CHAVE: Educação Física, Diretrizes Curriculares, formação de professores.

\section{SOBRE AS DIRETRIZES CURRICULARES PARA O ENSINO SUPERIOR BRASILEIRO}

um país em que a modernidade sempre andou lado a lado com a
manutenção das mais atrasadas estruturas oligárquicas, o Estado tem quase sempre mantido com a sociedade civil uma relação de cooptação e/ou de exclusão de participação desta última nas decisões mais importantes de cunho político, econômico e educacional. E, portanto, uma relação marcada claramente por uma cultura autoritária por parte de nossas elites dirigentes, logo não é de se estranhar que, mais uma vez, reformas em nosso sistema de ensino superior ocorram via processos tanto de cooptação quanto de exclusão na participação na tomada de decisões. A esse respeito a Prof ${ }^{a}$ Celli Taffarel (1998, p. 9) comenta que:

estabelecem-se prazos irrisórios para a definição de Diretrizes Curriculares. O Edital de convocação expedido em 10 de novembro (1998) estabelece como prazo de apresentação de propostas 2 de março de 1999, o equivale a três meses, nos quais - dezembro, janeiro e fevereiro - são de recesso escolar, festividades natalinas de final de ano e de férias docentes. Levantando dados junto a associações envolvidas na elaboração de Propostas Básicas para Projetos de formação profissional, constatamos prazos bem mais ampliados. Por exemplo: A ABES - Associação Brasileira de Ensino e Serviço Social -, elaborou uma "Proposta Básica para o Projeto de Formação Profissional", submetido a comissão de especialistas SESu/MEC, sendo aprovada, que decorreu de grande mobilização, envolvendo 72 unidades de ensino de serviço social e, exaustivos debates em uma série de eventos - 200 Oficinas locais, 25 regionais Duas nacionais -, criando condições para a participação das Unidades de Ensino na elaboração das Novas Diretrizes, aprovadas em assembléia com participação de $80 \%$ das Unidades de Ensino. Isto ocorreu no período de 1994 a 1996, ou seja três anos e não três meses como exige a SESu/MEC. Para chegar a formulação da Resolução 003/87 que 
reordenou a formação profissional em educação física, por exemplo, constatamos aproximadamente 10 anos de debates dos profissionais da área (1977 a 1987).

Por outro lado, também é verdade que nossa história é atravessada por importantes episódios de participação democrática, com autonomia, maturidade, senso crítico e criatividade por parte da sociedade civil organizada, em especial dos setores democráticos das universidades públicas brasileiras. Um exemplo disto é a construção do Plano Nacional de Educação a partir de dois Congressos Nacionais de Educação (CONEDs), realizados em Belo Horizonte (MG) em 1996 e 1997, com ampla participação de entidades científicas, sindicais e educacionais.

Assim, amparados por esta leitura prévia e circunscrita aos limites deste texto, pensamos que os processos de elaboração de Diretrizes Curriculares para o ensino superior no país indicam uma necessidade de afirmação de uma ação - que integra um conjunto de medidas vinculadas ao Programa Nacional de Graduação (PNG) do MEC - que tem a intenção de modernizar a vida universitária brasileira, especialmente quando sabemos que os padrões e referências estabelecidos pela Reforma Universitária de 1968 há muito se esgotaram. Entretanto, estas mesmas iniciativas de "modernização" são acompanhadas por iniciativas que visam 'quebrar' a autonomia universitária (PEC 370/96), bem como levar às últimas conseqüências a privatização de universidades públicas.

Desta forma, em primeiro lugar, pensamos que é um equívoco não analisar esta conjuntura que estamos vivendo, para que possamos tomar decisões de forma mais esclarecida, crítica e autônoma. Em segundo lugar, pensamos que decisões sobre currículo há muito deixaram de contemplar apenas aspectos técnicos, metodológicos e de procedimentos, o que sempre caracterizou uma visão tecnocrática, racionalista e produtivista de currículo. Esta visão tecnocrática foi entre nós implantada através dos acordos MEC/USAID nos anos 60-70.

Hoje, por meio da visão empresarial de universidade e da sua correlata noção de qualidade total, o MEC e seus parceiros internacionais - leia-se o Banco Mundial e o FMI -, procuram novamente racionalizar a vida acadêmica brasileira, numa versão "pós-moderna" da tecnocracia, ou ainda numa espécie de neotecnicismo. De fato, percebemos 
claramente a ingerência do Banco Mundial no PNG do governo brasileiro, senão vejamos:

O Banco Mundial não apresenta idéias isoladas mas uma proposta articulada - uma ideologia e um pacote de medidas (...) de reformas, propostas aos países em desenvolvimento que abrange um amplo conjunto de aspectos vinculados à educação, das macropolíticas até a sala de aula, políticas estas que declaram o objetivo de elevação da qualidade do ensino, enquanto implementam a redução dos gastos públicos para a educação e mantêm-se indiferente à carreira docente e ao salário do magistério. (WARDE \& HADDAD, 1996, p. 12).

Todavia, atualmente, qualquer discussão sobre currículo numa perspectiva crítica e consistente, para além das questões referentes a técnicas, métodos e procedimentos, não pode jamais deixar de abordar aspectos epistemológicos, sociológicos, políticos e culturais do currículo. Daí por que acreditamos ser necessário romper com a falta (até então) de uma maior discussão a respeito do currículo a partir destas duas referências essenciais:

- o contexto histórico atual, com especial ênfase nas questões relativas à autonomia universitária e às privatizações;

- as teorias críticas do currículo, com ênfase tanto nos aspectos técnicos e metodológicos quanto nos referentes à ideologia, ao poder e à cultura no currículo.

Finalmente, por tudo isto, sugerimos que o debate sobre as Diretrizes Curriculares para o ensino superior no país não seja separado das discussões relativas aos problemas mais amplos de nossas universidades públicas neste momento e que, ao invés de investirmos em "modelos" de currículo universalmente válidos, apontemos (após debates, estudos, discussões etc.) princípios orientadores para o ensino superior. Afinal, devemos apostar não na descoberta de "fórmulas" mágicas que nos indicariam algum currículo transcendente e atemporal e, sim, na variedade de currículos que podem e devem surgir das proposições das pessoas diariamente envolvidas em suas lutas específicas e em situações concretas. Segundo Taffarel (1998, p. 9),

impõe-se como imperativo da consciência histórica da classe quevive-do-trabalho, que não cabe ao Governo a ingerência sobre 
construção de Diretrizes, mas sim garantir o financiamento para que, com autonomia científica e pedagógica, com base em processos coletivos internos, democráticos, com ampla participação e representação construam-se eixos norteadores comuns a nível nacional para a formação acadêmica, inicial e continuada, cujo referencial seja o padrão unitário de qualidade na formação acadêmica.

Além disto, também queremos reiterar nossa postura de que há muito estão se confrontando dois projetos antagônicos para a universidade brasileira. No projeto defendido pelos amplos setores democráticos de nossa sociedade, interessados na soberania nacional, prevalece a visão de que são necessárias medidas, tais como reajuste e aumento salarial seguidos da implementação séria de uma política de capacitação docente e de que é dever e obrigação do Estado manter nosso sistema de ciência e tecnologia via universidades públicas etc.. No outro projeto, estabelecido pelo Banco Mundial e aceito pelo governo brasileiro, pelo MEC, pelo SESu e pelo MARE, bem como por alguns setores privatistas internos na universidade pública brasileira, prevalece a visão de não-reajuste e aumento para os servidores públicos, mantendo-se o magistério à base de 'bolsas' de incentivo e gratificações segundo a 'produtividade', com ausência de uma política consistente de capacitação docente, sem falar na desobrigação progressiva do Estado para com o ensino público e a conseqüente deterioração da ciência e da tecnologia do país, entre outros pontos.

É somente no contexto deste embate de projetos que podemos captar a essência do debate acerca das diretrizes curriculares. Com efeito, podemos visualizar, com base no texto da Prof ${ }^{a}$ Celi Taffarel, o embate de projetos com: a) Fundamentação Teórica: Governo - enfoque no perfil, na competência, nas habilidades, no individualismo, na adaptação ao mercado versus objetivos-avaliação na formação humana, profissional, com base nas necessidades da sociedade e na transformação social, no mundo do trabalho; b) Referências éticas (móvel da conduta humana e profissional): Governo - o capital, o mercado mundializado, a globalização da economia versus a luta histórica da classe que vive do trabalho pela emancipação humana e de classes; c) Justificativas: Governo - sintonizar a universidade com uma nova ordem mundial, sintonia com paradigmas do mundo moderno, científico-tecnológico 
versus sintonia com as aspirações das amplas massas, pelas transformações sociais do modo de produção capitalista; c) Organização do conhecimento: Governo - em disciplinas versus em ciclos, com critérios relacionados à relevância social; d) Concepção de formação: governo propedêutica/etapista, os cursos seqüenciais, os aligeiramentos versus formação integralizadora, contínua, inicial e continuada, espiralada, totalizante - de totalidade, de conjunto e de aprofundamento, com consistente base teórica; e) Concepção de reforma curricular: Governo - rever estrutura e natureza do currículo versus alterações significativas na organização do processo de trabalho pedagógico; f) Núcleo obrigatório: Governo - definição de percentual máximo comum obrigatório de $50 \%$ versus referência no padrão nacional de qualidade; g) Modelos e padrões de referência: Governo - modernização, universidade de serviço e docência e pesquisa de resultados, privatizante e terceirizada versus trabalho autônomo e autonomia criadora, dimensão pública da pesquisa tanto na sua realização quanto na destinação dos resultados.

\section{SOBRE AS DIRETRIZES CURRICULARES PARA OS CURSOS DE GRADUAÇÃO DE EDUCAÇÃO FÍSICA*}

A FEF/UFG foi uma das instituições acadêmicas a se pronunciar com relação às Diretrizes Curriculares específicas de nossa área profissional, assumindo inclusive uma postura crítica e propositiva. A Faculdade enviou ao MEC um documento intitulado "Diretrizes curriculares para

1. Como se sabe, o MEC nomeou uma comissão de especialistas da área de Educação Física (bem como para todas as demais áreas) para elaborar as Diretrizes Curriculares neste âmbito, sinalizando assim às IFES para que procedessem a uma reforma curricular e do conjunto de seu sistema acadêmico, o que deve ocorrer com todos os cursos de graduação do país. Atendendo a solicitação do $\mathrm{MEC} /$ comissão de especialistas da área e da própria Reitoria da UFG, a FEF designou esta comissão para estudos de currículo. Elaboramos este documentosíntese como forma de contribuição para o debate e de apresentação de sugestões, já tendo inclusive encaminhado o mesmo para ambos os órgãos. Agora, com mais esta publicação (os documentos da FEF aqui mencionados já estão à disposição na Internet - home page do MEC e da Reitoria UFG), esperamos ampliar o debate com os mais diferentes setores da Educação e do Esporte em Goiás, interessados em novos rumos que certamente a formação de professores tomará daqui em diante. 
o ensino superior: contribuição para o debate em Educação Física", em que fundamenta sua posição e suas propostas.

Tal como já havíamos afirmado no documento anterior, mais uma vez entendemos ser indispensável refletir sobre as Diretrizes Curricula- res para o Ensino Superior de Educação Física, a luz das considerações já realizadas neste texto sobre a própria política de implementação de Diretrizes Curriculares para o Ensino Superior em geral, sendo desnecessário retomá-las aqui. Por isto, vamos apenas sublinhar novamente alguns aspectos que pensamos ser fundamentais:

- Entendemos que um padrão único de qualidade para a formação superior em Educação Física passa necessariamente pela defesa da formação de um único profissional na área. Esta formação única conteria ainda o aprofundamento em áreas de conhecimento ofertadas pelo próprio currículo, como veremos mais adiante. Assim, sugerimos que o perfil do egresso dos cursos de Educação Física contemple: 1) a compreensão e a intervenção de forma crítica na construção e sistematização histórico-social das mais diversas formas de manifestação, linguagem e expressão corporal, exteriorizadas nas formas de ginástica, jogos, danças, esportes, entre outros, bem como nas mais diversas formas de instalações e equipamentos materiais, tecnologias, produção artística e literária relacionada aos interesses sócio-culturais das sociedades contemporâneas neste setor; 2) a superação das manifestações e práticas corporais que, na atualidade, possam representar meios de alienação cultural, exploração do trabalho, degradação ambiental, agressão à promoção da saúde, entre outros; 3) o compromisso com a socialização dos saberes científicos sobre a cultura corporal, respeitando as diversidades próprias da cultura humana, além de incentivar a construção de novas formas de manifestação e práticas corporais; 4) a adoção de uma postura não só de consumo crítico e sistematização do conhecimento já produzido, mas também de produção de conhecimento novo, identificado com os princípios anteriormente citados e, em especial, com a resolução de problemas decorrentes da prática pedagógica no âmbito da Educação Física.

- Defendemos uma proposta curricular que, por um lado, rejeita a concepção de conhecimento fragmentado, divido em etapas, com caráter de terminalidade e linear e, por outro, o entende como algo 
que se desenvolve em espiral. Assim, discordamos da noção de módulos e pré-requisitos de conhecimento, e preferimos blocos de conhecimento, nos quais o saber, originado nos mais distintos campos de conhecimento como o científico, o artístico, o filosófico e o bom senso (núcleo válido do senso comum) por exemplo convergiria dentro do princípio da unidade metodológica, permitindo ao acadêmico construir referências cada vez mais amplas sobre aquele módulo (por exemplo sobre a corporeidade, motricidade humana, jogo, lazer, saúde, corpo e sociedade, esporte e meio ambiente ...).

- Preocupa-nos, ainda, a designação do egresso dos cursos de Educação Física como um profissional e não como um professor de Educação Física, como se devêssemos nos identificar cada vez mais como profissionais liberais, e menos como educadores, na acepção mais profunda e relevante deste termo. Ainda que um professor de Educação Física não limite sua atuação profissional ao campo escolar, seu compromisso ético deve ser um só: o de educar. E, como sabemos, não é possível ter duas éticas, como, por exemplo, uma alinhada com o compromisso de socializar o saber elaborado, e outra que se submete a interesses mercadológicos de privatização do saber. Defendemos como designação do egresso dos cursos de Educação Física, a de educador, ou melhor, professor.

- Por fim, vale a pena deixar registrados novamente alguns aspectos importantes do documento anteriormente encaminhado pela FEF/UFG ao MEC:

2.1. Pressupostos a serem observados numa elaboração de diretrizes ou parâmetros para a construção de projetos curriculares

- O papel e a função social da universidade transcendem aos objetivos de mera transmissora e produtora de conhecimentos vinculados quase que exclusivamente ao mercado de trabalho. Isto significa que a universidade não pode tornar-se refém do mercado e, muito menos, a definição de perfil profissional deve ser circunscrita à sua lógica.

- O rompimento com a ideologia da neutralidade política do conhecimento e com a idéia neotecnicista da universalização da formação profissional preconizada por meio de transplantes 
científicos e culturais provenientes de modelos curriculares vindos do exterior. Tais ações buscam, no fundo, consolidar os instrumentos de interferência externa (neocolonialismo) no processo de desenvolvimento sócio-político, cultural, científico e tecnológico de nosso país.

- Os cursos de formação profissional devem superar as características tradicionais de meros reprodutores de conhecimento técnicos e de informações superficiais, para se transformarem em espaços prioritários de sistematização, transmissão e produção de conhecimentos e de intervenção social que dê sentido à uma prática profissional eficaz num projeto de formação científica, pedagógica e cultural voltada para a melhoria da qualidade de vida humana. Pesquisa, ensino e extensão deveriam constituir-se em elementos estruturais constitutivos do projeto acadêmico, e não apenas um discurso institucional.

\subsection{O Projeto curricular deve possibilitar ao acadêmico:}

- Compreender a realidade econômica, política e sócio-cultural brasileira no sentido de situar a sua prática educativa, as relações profissionais inscritas no contexto social e os nexos que são estabelecidos com a educação.

- Apropriar-se dos processos de sistematização, de organização, de produção dos saberes pedagógicos, tomando, como referência, os problemas gerados a partir da prática educativa.

- Instrumentalizar-se a partir das metodologias do trabalho pedagógico que busquem a interdisciplinaridade e uma maior eficiência na articulação da teoria com a prática.

\subsection{Quanto às competências}

- A prática social deve servir como ponto de partida para que sejam estruturados os campos de ação profissional: demandas sociais, locais de atuação, perspectiva de expansão de mercados de trabalho, inovações e o desenvolvimento científico da área, entre outros.

- A opção pelos conhecimentos científicos é que deverá sustentar a leitura mais adequada para demonstrar, explicar e compreender a realidade dada. Em todos esses procedimentos, as instituições 
formadoras deverão lançar mão de um trabalho coletivo que seja capaz de dimensionar o processo de análise e de avaliação no sentido de operar, objetiva e qualitativamente, o processo de construção curricular.

2.4. Modelo de estrauturação do curso a ser pensado pelo coletivo

- O curso de formação profissional em Educação Física deve ser estruturado ou constituído de tantos módulos quantos forem necessários, desde que, em cada um deles, estejam expressos os significados teórico-filosóficos, a metodologia, as opções conceituais, a avaliação e suas finalidades no contexto do projeto de formação, bem como de que forma serão realizadas as suas articulações com o ensino, com a extensão e com a pesquisa.

2.5. Flexibilidade e aprofundamento de conhecimentos na formação científico-cultural ...

- O curso de Educação Física, além de objetivar a preocupação com a formação continuada de seus profissionais, deverá ser flexível na sua organização curricular. Isto significa que o contexto curricular deve abrir possibilidades ao aluno de construir, a partir de seus interesses acadêmicos, a participação em outras disciplinas ministradas por outros cursos da universidade, sob a forma de disciplinas especiais (optativas), para a ampliação de conhecimentos.

\section{COMENTÁRIOS FINAIS}

A história da formação de professores de Educação Física pode ser encarada sob muitos aspectos, caracterizados por fases pelas quais ela já passou e passa, bem como pelo confronto de perspectivas e concepções que cada período alimentou. Assim, em seus primórdios, quando da fundação da primeira escola de Educação Física civil no país, em 1939 - Escola de Educação Física e Desportos (EEFD), da antiga Universidade do Brasil, atual UFRJ -, a formação de professores de Educação 
Física conheceu sua primeira grande fase: a do currículo padrão. ${ }^{2}$ Neste, o confronto se deu basicamente entre médicos e militares de um lado e, de outro, os primeiros professores civis que se formavam e passavam a disputar espaço no interior da Escola a partir de outras referências, que começavam a se distanciar (mesmo que de forma tênue inicialmente) das concepções médico-militares.

Com o fim do currículo padrão, que vigorou por trinta anos (de 1939 a 1969) e com a implantação do currículo mínimo para os cursos de graduação em Educação Física pelo MEC, inicia-se a segunda grande fase da formação docente na área. Agora, o conflito de concepções se dá entre a visão esportivizante desta formação e uma visão de cunho mais pedagógico-educacional, que emergiu, sobretudo, na década de 80 .

Em 1987, como sabemos, encerra-se o currículo mínimo e passa a vigorar - novamente de acordo com legislação vinda do Conselho Federal de Educação/MEC, mas agora sob forte pressão dos movimentos e professores de Educação Física, o currículo por áreas de conhecimento (áreas técnico-esportiva, biológica, sócio-filosófica e didático-metodológica). Nesta terceira grande fase o confronto se dá basicamente entre as concepções mais próximas à licenciatura e aquelas que viam no bacharelado uma alternativa.

Finalmente, na atualidade, com o esgotamento do modelo de currículo por áreas de conhecimento, sobretudo diante das novas demandas que o mercado capitalista estabelece para a área de Educação Física/Esportes, o MEC novamente intervém, propondo uma quarta grande fase da formação de professores na área: a fase dos cursos de graduação segundo as Diretrizes Curriculares. Nesta nova etapa, o conflito entre demandas mercadológicas, concepções fragmentárias de formação docente e mesmo o aligeiramento desta por um lado e, por outro, uma formação, segundo os princípios que a FEF/UFG defende em seus documentos (que, vale lembrar, são contribuições para o debate), começa a despontar.

Torna-se extremamente necessário intervirmos neste debate, ampliando os fóruns públicos de discussão, apresentando propostas, nos 2 O currículo da EEFD foi estabelecido como padrão para todas as demais escolas de
Educação Física. 
reunindo com nossos colegas docentes nas escolas, universidades e em todos os demais locais de trabalho, com o objetivo de nos esclarecer mais e melhor sobre esta questão tão importante. E, sobretudo, tendo a clareza de que somos sujeitos de mais este momento histórico pelo qual passa o processo de formação de professores de Educação Física. Abdicar deste direito pode significar deixar nossos currículos sob a direção de interesses, que podem não ser os interesses de uma educação democrática e de uma sociedade justa, por que tanto lutamos.

\section{ABSTRAT}

In this paper e make considerations about the curriculum diretrixes for universities, mainly those related to Physical Education. We believe that the diretrixes, established by a commission of experts, need discussion. We oppose to Worsd-Wide Bank, IMF and MEC due to their merchandising interests. We understand that the formation of teachers needs to take place in a public, free and socially qualified university. This paper also presents FEF's contrubutions to this discussion, extracted from a document (not published yet). Our points of view concerning curriculum and tracher's graduation are discussed in detail.

\section{REFERÊNCIAS BIBLIOGRÁFICAS}

DAVID, Nivaldo A. et al. Diretrizes Curriculares Nacionais para o Ensino Superior: contribuições para o debate em Educação Física. Goiânia: FEF/UFG, 1998.

TAFFAREL, Celi. As Diretrizes Curriculares no Programa Nacional de Graduação: o assalto às consciências e o amoldamento subjetivo. Recife: UFPe, 1998. (mímeo).

WARDE \& HADDAD. O Banco Mundial e as politicas educacionais. São Paulo: Cortez, PUC, Ação Educativa, 1996. p. 125-193. 